\title{
ARTICLE
}

\section{IGF-1 receptor cleavage in hypertension}

\author{
Selma Cirrik ${ }^{1}$ - Geert W. Schmid-Schönbein ${ }^{2}$
}

Received: 1 March 2017 / Revised: 8 September 2017 / Accepted: 18 October 2017 / Published online: 19 March 2018

(c) The Author(s) 2018. This article is published with open access

\begin{abstract}
Increased protease activity causes receptor dysfunction due to extracellular cleavage of different membrane receptors in hypertension. The vasodilatory effects of insulin-like growth factor-1 (IGF-1) are decreased in hypertension. Therefore, in the present study the association of an enhanced protease activity and IGF-1 receptor cleavage was investigated using the spontaneously hypertensive rats (SHRs) and their normotensive Wistar Kyoto (WKY) controls $(n=4)$. Matrix metalloproteinase (MMP) activities were determined using gelatin zymography on plasma and different tissue samples. WKY aorta rings were incubated in WKY or SHR plasma with or without MMP inhibitors, and immunohistochemistry was used to quantify the densities of the alpha and beta IGF-1 receptor (IGF-1R) subunits and to determine receptor cleavage. The pAkt and peNOS levels in the aorta were investigated using immunoblotting as a measure of IGF-IR function. Increased MMP-2 and MMP-9 activities were detected in plasma and peripheral tissues of SHRs. IGF-1R beta labeling was similar in both groups without plasma incubation, but the fraction of immunolabeled area for IGF-1R alpha was lower in the endothelial layer of the SHR aorta $(p<0.05)$. A 24-h incubation of WKY aorta with SHR plasma did not affect the IGF-1R beta labeling density, but reduced the IGF-1R alpha labeling density in the endothelium $(p<0.05)$. MMP inhibitors prevented this decrease $(p<0.01)$. Western blot analyses revealed that the pAkt and peNOS levels under IGF-1-stimulated and -unstimulated conditions were lower in SHRs $(p<0.05)$. A reduced IGF-1 cellular response in the aorta was associated with the decrease in the IGF-1R alpha subunit in the SHR hypertension model. Our results indicate that MMP-dependent receptor cleavage contributed to the reduced IGF-1 response in SHRs.
\end{abstract}

\section{Introduction}

Insulin-like growth factor-1 (IGF-1) is an insulin homolog protein that regulates growth, differentiation and metabolism. The primary source of IGF-1 is the liver under control of growth hormone [1, 2]. Local production of IGF-1 in different tissues, including vascular smooth muscle cells and endothelial cells, exhibits endocrine and paracrine regulatory roles in cardiovascular physiology and pathophysiology [3-5].

IGF-1 also participates in the regulation of regional blood flow and blood pressure via stimulation of endothelial nitric oxide synthase (eNOS) activity and nitric oxide (NO)

Selma Cirrik

selmacrrk@yahoo.com

1 Department of Physiology, Faculty of Medicine, Ordu University, Ordu, Turkey

2 Department of Bioengineering, University of California San Diego, La Jolla, CA 92093-0412, USA production in endothelial cells [6-10]. IGF-1 increases blood flow via vasodilation in rats, and mice with genetic IGF-1 deficiency exhibit elevated mean blood pressure, which supports the role of this growth factor in blood flow and pressure regulation [9-11]. Notably, serum IGF-1 levels are high in hypertensive subjects and mediate structural adaptive changes, such as ventricular hypertrophy and vascular remodeling [4]. A reduction in the vascular relaxation response to IGF-1 was reported in hypertension [12-14]. Ex-vivo studies in spontaneously hypertensive rats (SHRs) revealed reduced IGF-1-mediated vasodilatation in the aorta, and IGF-1 did not exert regulatory effects on renal hemodynamics in SHRs [12-14]. These results suggest that the reduced vascular response to IGF-1 may play an important role in the development of arterial hypertension.

Hypertension is a risk factor for mortality and morbidity $[15,16]$. Recent studies demonstrated that increased proteinase activity, including matrix metalloproteinases (MMPs), may be important in the loss of cellular function and end-organ damage in hypertension [17-21]. Clinical data support a role for plasma MMP-2 and MMP-9 levels as novel predictors of cardiovascular risk [22-24]. Increased 
MMP activity, including MMP-2, MMP-9 and MMP-7, leads to cleavage of cell membrane receptors in hypertension [17, 18, 25]. MMP cleavage of the extracellular domain of plasma membrane receptors produces a loss of receptor response, followed by loss of the associated cell function [19]. Cleavage of the $\beta_{2}$-adrenergic receptor by enhanced MMP activity in the SHR plays an important role in hypertension development. In the same hypertensive rat strain, insulin receptor cleavage produces type II diabetes, vascular endothelial growth factor receptor 2 (VEGFR-2) cleavage induces endothelial apoptosis and reduces capillary density (rarefaction) [19-21, 25]. Notably, chronic treatment with MMP inhibitors reduced receptor cleavage, blood pressure and insulin resistance in SHRs and increased capillary density, which supports the importance of increased MMP activity in the pathophysiology of hypertension and its comorbidities [19, 20]. A similar mechanism of proteolytic receptor cleavage is observed in other comorbidities, such as deficiencies in immune function (e.g., leukocyte adhesion), leukocyte mechanotransduction, macrophage functions and cleavage of the glycocalyx in SHRs [26-30].

The IGF-1 receptor (IGF-1R) is a heterotetrameric receptor that is structurally similar to the insulin receptor. The extracellular alpha subunits of the receptor bind ligands, and the transmembrane beta subunits exhibit tyrosine kinase activity $[2,4]$. Veccihone et al. found no shift in the protein levels of the IGF-1R beta subunit in the SHR aorta, but they demonstrated a reduced vasodilatation response to IGF-1 [13]. These authors did not investigate IGF-1R alpha subunit protein levels despite the apparent receptor insensitivity. We hypothesize that increased MMP activity in hypertension results in the proteolytic cleavage of the extracellular IGF-1R alpha subunit and the observed insensitivity. Therefore, our study investigated the level of proteolytic cleavage of the IGF-1R in SHRs.

\section{Methods}

\section{Animals}

Male Wistar Kyoto Rats (WKY) and SHRs (Harlan Laboratories Inc., Indianapolis, IN, USA) were used at 8 weeks of age ( $n=4$ per group). The SHR hypertension model used in this study is highly reproducible, and consistent results are achieved in small sample sizes, such as 3 or 4 animals [25, 29, 30]. The Institutional Animal Care and Use Committee (IACUC) at the University of California, San Diego approved all animal protocols. General anesthesia (sodium pentobarbital $50 \mathrm{mg} / \mathrm{kg}$, i.m., Abbott Laboratories, North Chicago, IL, USA) was induced, and femoral venous and arterial catheters (PE-50 tubing, Clay
Adams, Parsippany, NJ, USA) were introduced for vascular access and continuous blood pressure measurements, respectively (MACLAB, GE Medical Systems, Milwaukee, WI, USA). Whole blood was drawn from the arterial catheter, and the thoracic aorta, kidney, heart, liver and spleen were harvested after euthanasia. The dissected aorta was placed in cold phosphate-buffered saline (PBS) buffer, cleaned of the adhering perivascular tissue and cut into 2-3$\mathrm{mm}$-long rings. The fresh aorta rings were used in receptor cleavage and receptor function experiments. Other tissues were homogenized and centrifuged at $13,000 \mathrm{~g}$ at $4{ }^{\circ} \mathrm{C}$ for $10 \mathrm{~min}$. Supernatants were aliquoted and stored at $-80^{\circ} \mathrm{C}$ until protein determinations and gelatin zymography were performed.

\section{Gelatin zymography}

MMP-2 and MMP-9 activities were determined by molecular weight using gelatin zymography. Briefly, sodium dodecyl sulfate (SDS) gels (10\% acrylamide/bis) with gelatin $(0.8 \mathrm{mg} / \mathrm{ml})$ were loaded with plasma samples $(1.5$ $\mu \mathrm{l})$ or homogenates of kidney, heart, liver and spleen (40 $\mu \mathrm{g})$ and run $(110 \mathrm{~V}$, constant voltage $)$ for $80 \mathrm{~min}$. Gels were washed three times with renaturing buffer $(2.5 \%$ Triton $\mathrm{X}$ 100) and incubated in renaturing buffer for $60 \mathrm{~min}$ at room temperature. Gels were equilibrated in the developing buffer (50 mM Tris- $\mathrm{HCl}, \mathrm{pH} 7.8 ; 0.2 \mathrm{M} \mathrm{NaCl}, 5 \mathrm{mM} \mathrm{CaCl}_{2}$ and $0.02 \%$ Brij 35) for $30 \mathrm{~min}$ at room temperature and incubated in fresh developing buffer overnight at $37^{\circ} \mathrm{C}$ to allow for enzymatic digestion of the gelatin. Gels were stained ( $0.25 \%$ Brilliant Blue R, 50\% methanol and $20 \%$ acetic acid in $\mathrm{dH}_{2} \mathrm{O}$ ) for $60 \mathrm{~min}$ and de-stained with type-I destaining solution (methanol:acetic acid:water, 50:10:40) for $60 \mathrm{~min}$ while shaking. Gels were de-stained with type-II destaining solution (methanol:acetic acid:water, 10:10:80) until transparent bands appeared above the blue background. Gels were placed on a light table, and protein band images were captured using a digital camera. The intensity of the transparent bands was densitometrically quantified using Image $\mathbf{J}$ (version 1.41; National Institutes of Health, Bethesda, MD, USA).

\section{IGF-1R cleavage}

In all, 2-3 mm of fresh aorta rings of WKY rats were incubated with WKY or SHR plasma at $37^{\circ} \mathrm{C}$ for $24 \mathrm{~h}$ with or without protease inhibitors (EDTA $10 \mathrm{mM}$, doxycycline $11.3 \mu \mathrm{M})$ to investigate the cleavage of IGF-1R in thoracic aorta. Aortic rings were fixed in formalin (10\%), and the densities of IGF-1R alpha and beta subunits were determined using immunohistochemistry (IHC).

Paraffin-embedded aorta samples were sectioned at a thickness of $6 \mu \mathrm{m}$ for IHC. Sections were deparaffinized in 


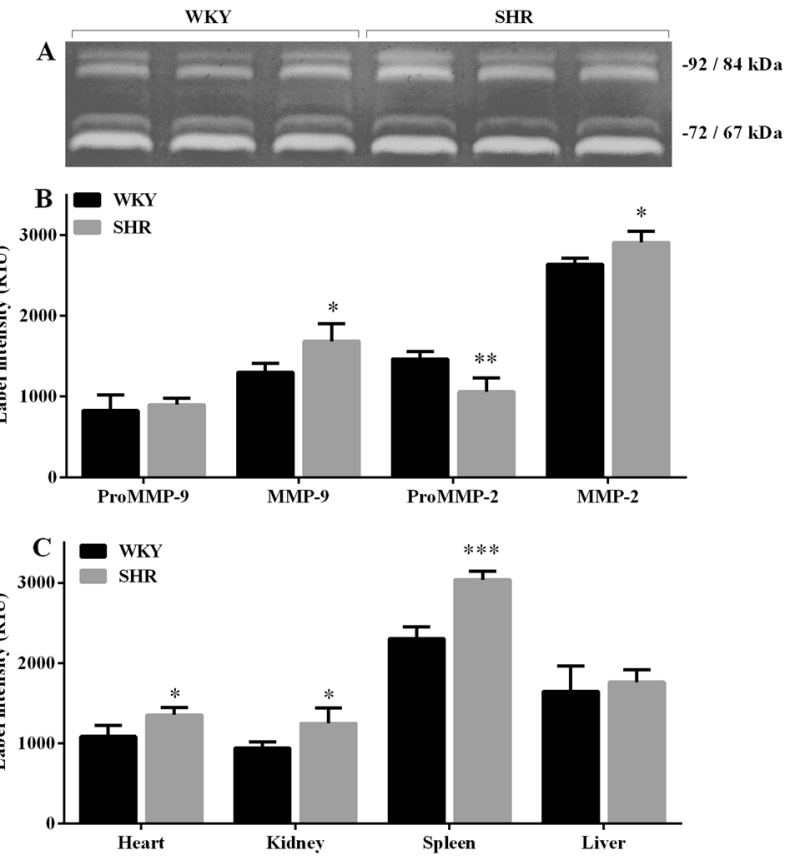

Fig. 1 Gelatinolytic activities in plasma and tissue samples from WKY and SHRs. Bar graphs show the means \pm SD of the gelatinolytic band densities $(n=4)$. Gelatin zymography gels used to quantify the plasma pro-MMP-9, MMP-9, pro-MMP-2 and MMP-2 activities a. Plasma MMP activities b. MMP-9 activity in heart, kidney, spleen and liver homogenates c. ${ }^{*} p<0.05,{ }^{* *} p<0.01,{ }^{* * *} p<0.001$ compared with WKY

xylene, dehydrated in a graded ethanol series, and boiled in glycine buffer $(0.05 \mathrm{M}, \mathrm{pH}$ : 3.5) for $15 \mathrm{~min}$ for antigen retrieval. Endogenous peroxidase activity was blocked via incubation in $3 \% \mathrm{H}_{2} \mathrm{O}_{2}$. Sections were blocked in $0.1 \%$ BSA and incubated with a mouse anti-rat IGF-1R alpha monoclonal antibody (1:400; Santa Cruz Biotechnology Inc., Santa Cruz, CA, USA; catalog number sc-463) or rabbit anti-rat IGF-1R beta polyclonal antibody (1:100; Cell Signaling Technology Inc., Beverly, MA, USA, catalog number 3027) overnight at $4{ }^{\circ} \mathrm{C}$. Slides were washed in Tris-buffered saline (TBS) and incubated with a horseradish peroxidase (HRP)-conjugated goat anti-rabbit IgG antibody (Santa Cruz Biotechnology Inc., Santa Cruz, CA, USA; catalog number sc-2004) or goat anti-mouse IgG antibody (Santa Cruz Biotechnology Inc., Santa Cruz, CA, USA; catalog number sc-2005) at a 1:500 dilution for $1 \mathrm{~h}$ at room temperature. Sections were incubated in a buffer containing 3, 3-diaminobenzidine tetrahydrochloride (DAB, Vector Laboratories Inc., Burlingame, CA, USA) to produce a brown reaction product. Slides were dehydrated and coverslipped. Sections were viewed under bright-field microscopy (Leica Dmd 108, Leitz Wetzlar, Germany, 20x objective). The labeled densities of aorta sections were determined digitally (Image J).

Label density measurements along the aortic wall were performed in the endothelial and smooth muscle layers.
Briefly, images of aortic sections containing all layers (tunica adventitia, media and intima) were recorded at equal magnifications, and the adventitial layer was deleted for this analysis. The remaining tunica media (smooth muscle cell layer) and tunica intima (endothelial layer) were selected and separately analyzed using Image J. The tissue area with immunolabels was digitally identified using a threshold pixel intensity that was selected above the pixel intensity of negative controls (without primary antibody). The immunolabeled tissue areas of the intima and media of each image were determined separately and normalized by the total tissue area. The results are presented as a percentage of total tissue crossectional area. Two to four different aortic sections per animal were labeled and analyzed to determine an average per rat (for a total of $n=4$ rats/group).

\section{IGF-1R function}

IGF-1-induced Akt and eNOS phosphorylation were determined using western blotting of fresh aorta rings from both rat strains to evaluate IGF-1R function. Aortic rings were incubated in HEPES buffer (pH 7.4) with or without IGF-1 $(100 \mathrm{nM})$ at $37^{\circ} \mathrm{C}$ for $20 \mathrm{~min}$. Tissues were homogenized and centrifuged at $13,000 \mathrm{~g}$ at $4{ }^{\circ} \mathrm{C}$ for $10 \mathrm{~min}$. Samples $(10$ $\mu \mathrm{g})$ were subjected to $10 \%$ SDS-polyacrylamide gel electrophoresis and transferred onto nitrocellulose membranes. Membranes were blocked in 5\% dry milk $(1 \mathrm{~h})$ and incubated overnight at $4{ }^{\circ} \mathrm{C}$ with the following primary antibodies: rabbit anti-rat peNOS pSer1177 monoclonal antibody (1:100, Thermo Fisher Scientific, Waltham, MA, USA, catalog number MA5-14957), rabbit anti-rat pAkt Ser473 monoclonal antibody (1:500, Cell Signaling Technology Inc., Beverly, MA, USA, catalog number 4060) and mouse anti-rat beta-actin monoclonal antibody (1:500, Santa Cruz Biotechnology Inc., Santa Cruz, CA, USA, catalog number sc-47778). Membranes were washed three times with TBS containing $0.1 \%$ Tween-20 (TBST), and an HRPconjugated goat anti-rabbit IgG antibody (Santa Cruz Biotechnology Inc., Santa Cruz, CA, USA; catalog number sc2004) or goat anti-mouse IgG antibody (Santa Cruz Biotechnology Inc., Santa Cruz, CA, USA; catalog number sc2005) was added at 1:2500 for $1 \mathrm{~h}$ at room temperature. Immunolabeling was visualized using ECL (Thermo Fisher Scientific, Waltham, MA, USA; SuperSignal ${ }^{\mathrm{TM}}$ West Pico Chemiluminescent Substrate). Band densities were analyzed using Image $\mathbf{J}$ and normalized to beta-actin.

\section{Statistical analysis}

All values are presented as the means \pm standard deviation. Statistical comparisons were performed using one-way analysis of variance followed by Newman-Keuls as a post 
hoc test, or Student's $t$-test. $p<0.05$ was considered significant.

\section{Results}

\section{Blood pressure}

The mean arterial blood pressure was $89 \pm 7 \mathrm{mmHg}$ in 8 week-old WKY rats and significantly elevated in the SHRs $(109 \pm 8 \mathrm{mmHg}, p<0.05)$.

\section{MMP activity}

Gelatin zymography was performed on plasma and tissue samples (i.e., heart, kidney, spleen and liver).

Gelatinolytic protease activities in the plasma samples were observed at approximately 92, 84, 72 and $67 \mathrm{kDa}$, which correspond to pro-MMP-9, MMP-9, pro-MMP-2 and MMP-2, respectively. The protease activities of MMP-9 and MMP-2 were increased in SHR plasma compared with WKY plasma $(p<0.05)$. Pro-MMP-2 activity was decreased in SHR plasma $(p<0.05)$, and pro-MMP-9 activity was not altered (Figs. 1a, b).

MMP-9 activity was detected in all tissue samples by gelatinolytic protease activities, and it was significantly higher in SHR heart $(p<0.05)$, kidney $(p<0.05)$ and spleen $(p<0.001)$. MMP-9 activity was not altered in the livers of SHRs (Fig. 1c).

MMP-2 activity was only detected in the liver and spleen. Liver MMP-2 activity was higher in SHRs (2163 \pm 61 vs. $2457 \pm 198$ relative intensity units (RIU), $\mathrm{p}<0.05)$, but it was similar in the spleens of the two strains (1412 \pm 49 vs. $1423 \pm 115$ RIU). Pro-MMP-2 activity in the spleen was elevated in SHRs (1432 \pm 230 vs. $1767 \pm 111$ RIU, $p<$ $0.05)$.

\section{Receptor cleavage of IGF-1R in SHRs}

Fresh aorta rings of WKY were exposed for $24 \mathrm{~h}$ to WKY or SHR plasma in the presence or absence of protease inhibitors to examine whether the increased plasma protease activity in SHRs cleaved the extracellular domain of IGF1Rs. Aortic rings were fixed after plasma incubation and labeled using IHC. Cleavage of the extracellular domain of IGF-1R was detected using antibodies against the intracellular carboxyl terminal of the transmembrane and extracellular domains of IGF-1R.

The percentage of IGF-1R alpha-labeled area along the tunica intima (endothelial) layer was lower in SHR aortic rings under non-incubated conditions (i.e., control; $p<$ 0.05). However, the percentage of immunolabeled area for IGF-1R alpha along the tunica media (smooth muscle cell

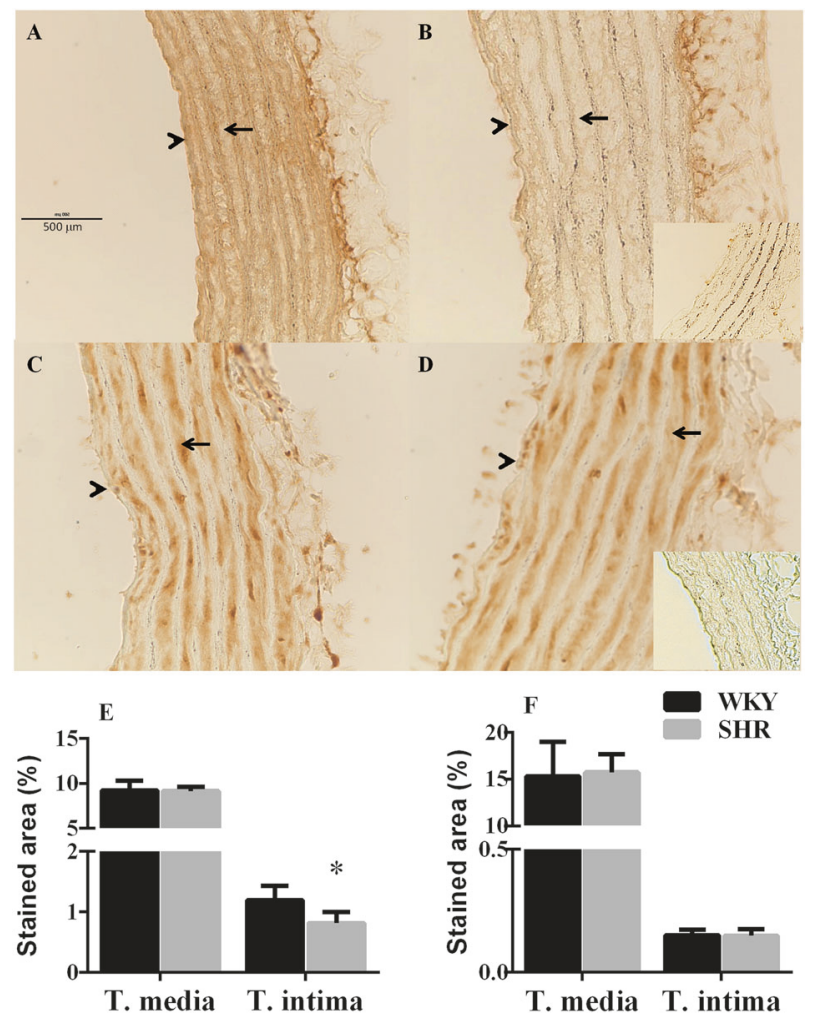

Fig. 2 Micrographs of aorta sections of WKY a, $\mathbf{c}$ and SHRs $\mathbf{b}, \mathbf{d}$ after IHC labeling with primary antibodies against IGF-1R alpha $\mathbf{a}, \mathbf{b}$ and beta $\mathbf{c}, \mathbf{d}$. Arrowheads show the endothelium, and arrows indicate the smooth muscle layer. Negative controls for IGF-1 alpha and beta IHC labeling are shown as smaller images. Means \pm SD of the percentage of stained area for IGF-1R alpha $\mathbf{e}$ and beta $\mathbf{f}$ in tunica intima (endothelium) and tunica media (smooth muscle cell) layers after IHC. The scale bar is $500 \mu \mathrm{m}$. *p<0.05 compared with WKY $(n=4)$

layer) was not different between WKY and SHR aortic rings. The percentage of labeled area for IGF-1R beta in endothelial and smooth muscle cell layers were identical in WKY and SHR aortic rings (Fig. 2).

A 24-h incubation of WKY aorta rings with SHR plasma decreases the percentage of labeled area of IGF-1R alpha in the endothelial layer compared with WKY plasma incubation $(p<0.05)$. The addition of protease inhibitors in the SHR plasma significantly increased IGF-1R alpha labeling in the endothelial layer ( $p<0.05$, Fig. 3 ). In comparison, the IGF-1R beta labeling in the endothelial layer was similar for all incubation conditions (Fig. 4).

IGF-1R alpha and beta labeling in the smooth muscle cell layer was similar in WKY and SHR plasma-incubated aortic rings (Figs. 3 and 4).

\section{IGF-1R function}

Aorta rings were incubated with or without IGF-1 (100 nM) for $20 \mathrm{~min}$ and pAkt and peNOS levels were determined using western analysis to examine whether the IGF-1- 

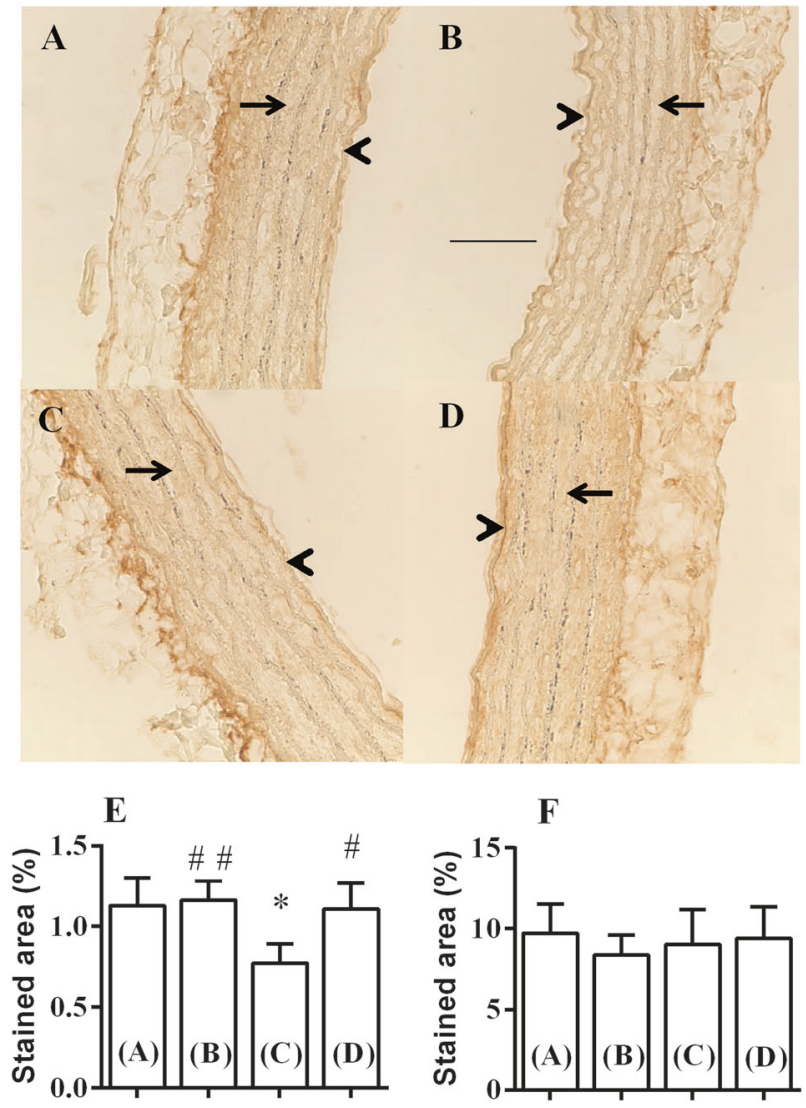

Fig. 3 Immunolabeling of WKY aorta sections with a primary antibody against the IGF-1R alpha subunit. Aortic rings were incubated with plasma from WKY $\mathbf{a}, \mathbf{b}$ or SHRs $\mathbf{c}, \mathbf{d}$ in the presence $\mathbf{b}, \mathbf{d}$ or absence a, c of protease inhibitors (EDTA $10 \mathrm{mM}$, doxycycline; 11,3 $\mu \mathrm{M})$ for $24 \mathrm{~h}$. Representative images are shown a-d. Arrowheads indicate the endothelium, and arrows indicate the smooth muscle layer. The scale bar is $500 \mu \mathrm{m}$. Bar graphs show the means \pm SD of the percentage of stained area using the same incubation conditions a-d in tunica intima (endothelium) e and tunica media (smooth muscle cell) layers $\mathbf{f}$. Two to four different aorta sections per animal were labeled to determine the average per rat $(n=4)$. The scale bar is $500 \mu \mathrm{m}$. ${ }^{*} p<$ 0.05 compared with WKY plasma-incubated rings; ${ }^{\#} p<0.05$ and $^{\# \#} p<$ 0.01 compared with SHR plasma-incubated rings

induced activation of the intracellular pathway of IGF-1R was different between WKY rats and SHRs.

pAkt levels were significantly lower in SHRs than WKY rats under the non-stimulated conditions (NS; without IGF$1 ; p<0.05)$. Akt phosphorylation increased significantly in WKY and SHR groups in the presence of $100 \mathrm{nM} \mathrm{IGF-1} \mathrm{(} p$ $<0.01$ and $p<0.05$, respectively). IGF-1-stimulated Akt phosphorylation was significantly more prominent in the WKY group compared with the SHR (Fig. 5).

peNOS levels were lower in SHRs than WKY rats under non-stimulated conditions $(p<0.001)$. PeNOS levels increased in WKY and SHR rings after IGF-1 incubation compared with non-stimulated conditions $(p<0.01$ and $p<$ 0.05 , respectively). PeNOS levels were significantly lower in SHR rings in the presence of IGF-1 $(p<0.001$; Figs. $5 c$, d).

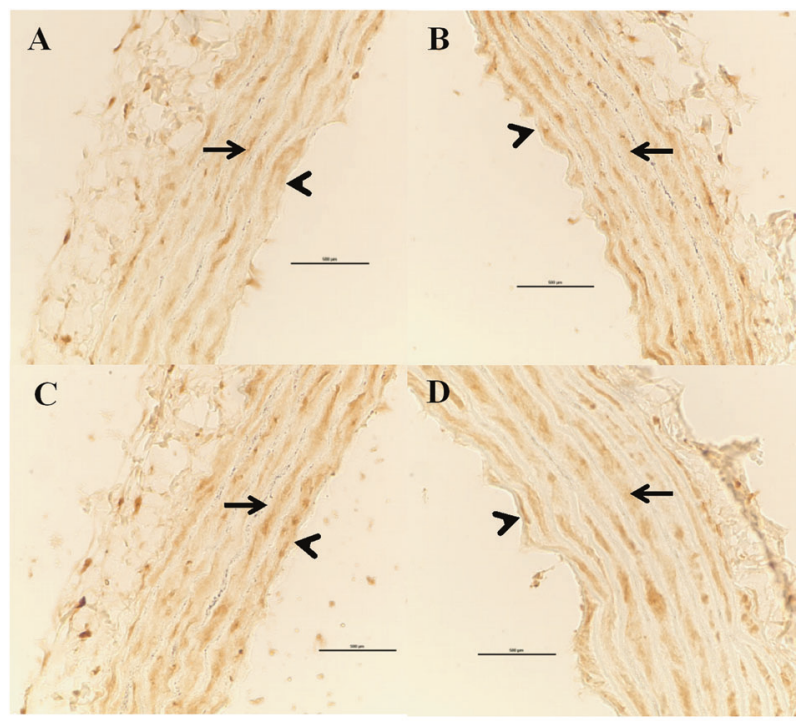

$\mathbf{E}$

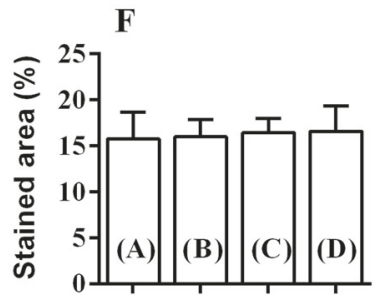

Fig. 4 Immunostaining of the aorta sections of WKY with a primary antibody against IGF-1R beta subunit. Aortic rings were incubated with plasma from WKY $\mathbf{a}, \mathbf{b}$ or SHRs $\mathbf{c}, \mathbf{d}$ in the presence $\mathbf{b}, \mathbf{d}$ or absence a, c of protease inhibitors (EDTA $10 \mathrm{mM}$, doxycycline; 11.3 $\mu \mathrm{M})$ for $24 \mathrm{~h}$. Representative images are shown a-d. Arrowheads show the endothelium, and arrows show the smooth muscle layer. The scale bar is $500 \mu \mathrm{m}$. Bar graphs show the means \pm SD of the percentage of stained area under the same incubation conditions a-d in tunica intima (endothelium) e and tunica media (smooth muscle cell) layers $\mathbf{f}$. Two to four different aorta sections per animal were labeled to determine the average per rat $(n=4)$. The scale bar is $500 \mu \mathrm{m}$

\section{Discussion}

The present study investigated whether high plasma protease activity induced cleavage of the extracellular ligandbinding domain of the IGF-1R in hypertension.

Previous studies provided evidence for increased MMP2, MMP-9 and MMP-7 activities in plasma, increased MMP-1, MMP-1/-9, MMP-7 and MMP-8 activities in the endothelial layer of mesenteric microvessels and increased MMP-2 activity in cardiac muscle of SHRs [17, 18, 31]. Our results showed increased MMP activity in plasma and different peripheral tissues, which indicated a general increase in protease activity in SHRs. MMPs are primarily responsible for extracellular matrix remodeling, and recent studies demonstrated that increased MMP activity produces receptor dysfunction due to the extracellular cleavage of several membrane receptors in hypertension, such as insulin, VEGFR-2 and $\beta_{2}$-adrenergic receptors [17-21]. The 
A

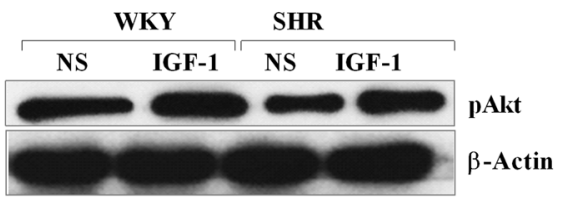

C

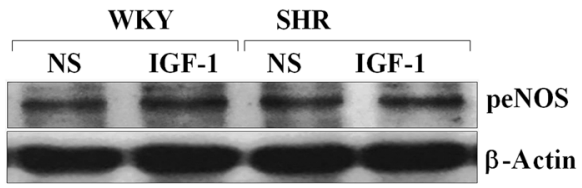

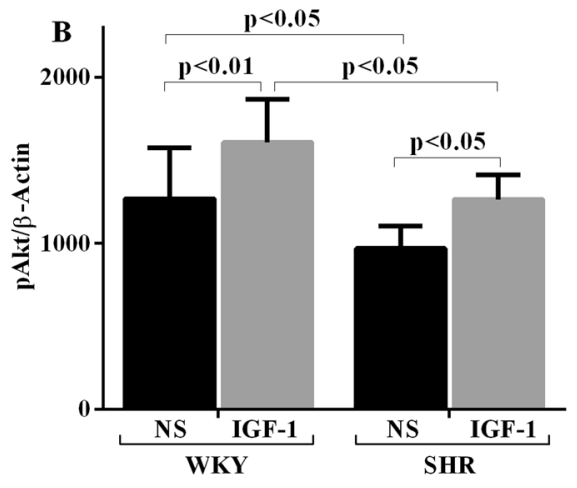

Fig. 5 p-AKT and peNOS levels in WKY and SHR aorta rings incubated in HEPES buffer at $37^{\circ} \mathrm{C}$ for $20 \mathrm{~min}$ in the presence (IGF-1) or absence (NS) of $100 \mathrm{nM}$ IGF-1. Representative images are shown a, c. An antibody against p-AKT recognized a band in the range of $60 \mathrm{kDa}$ a, an antibody against peNOS recognized a band in the range

functional deficiency of these receptors played important roles in situations related to hypertension comorbidities, such as insulin resistance, endothelial apoptosis, reduced capillary density and increased arteriolar and capillary resistance.

We incubated fresh aorta rings from WKY rats with WKY or SHR plasma for $24 \mathrm{~h}$ in the presence or absence of protease inhibitors to investigate whether increased protease activity in SHR plasma induced IGF-1R cleavage. IGF-1R beta immunostaining was similar in all incubation conditions in tunica intima (endothelium) or media (smooth muscle cell) layers. However, IGF-1R alpha labeling was significantly reduced in endothelial layers after incubation with SHR plasma. A reduction in receptor density was not observed after the 24-h incubation with SHR plasma in the presence of protease inhibitors. This result supports the hypothesis that high protease activity in SHR plasma induced receptor cleavage and revealed no receptor cleavage in the presence of protease inhibitors and increased IGF-1R alpha staining levels. The enhanced MMP-2 and MMP-9 activities in SHR plasma and potential cleavage sites for MMP-2 (2 different sites) and MMP-9 (42 different sites) in the IGF-1R alpha subunit suggest that MMPs contribute significantly to receptor cleavage (Appendix). IGF-1R internalization during SHR plasma incubation and regeneration during incubation with protease inhibitors may also occur because the peptide fragments produced by MMP activity were not measured in the incubation media or SHR plasma. This lack of measurement is a limitation of the current study, and more detailed experiments are needed (e.g., proteomic analysis).

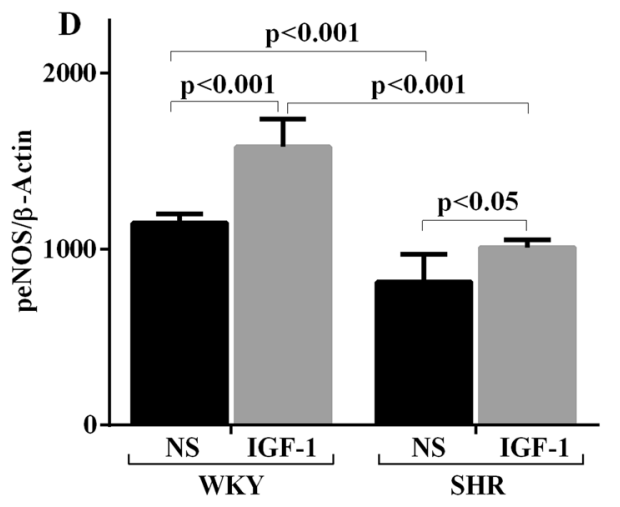

of $140 \mathrm{kDa}$ c, and the anti-beta-actin antibody recognized a band at $45 \mathrm{kDa}$ a, $\mathbf{c}$. The p-AKT and peNOS band densities were normalized to the respective beta-actin signal. Bar graphs show the means \pm SD of the band densities for p-AKT $\mathbf{b}$ and peNOS $\mathbf{d}(n=4)$

IGF-1 is a paracrine and endocrine factor that regulates growth, differentiation and cell survival [1, 2]. Increasing evidence suggests that IGF-1 possesses insulin-like metabolic effects, and decreased plasma levels are associated with obesity and metabolic syndrome [32]. IGF-1R signaling exhibits remarkable effects on cardiovascular physiology via regulation of endothelial functions and cardiac contractility, metabolism or hypertrophy [33-35]. IGF-1deficient mice exhibit elevated blood pressure [11], and humans with IGF-1 deficiency (i.e., Laron syndrome) exhibit an increased risk of stroke and cardiovascular diseases [32].

IGF-1 binding to IGF-1R increases receptor tyrosine kinase activity and triggers sequential intracellular events. Akt phosphorylation and activation (protein kinase B) are critical for eNOS phosphorylation and further NO production [3-5]. Reduction in IGF-1-mediated NO production contributes to the increase in blood pressure in hypertensive rats [12-14].

The current study investigated pAkt and peNOS levels in fresh aortic rings after incubation with exogenous IGF-1 to assess the response to IGF-1. Our study of receptor function demonstrated that pAkt and peNOS levels were low in the SHR group in the absence and presence of IGF-1. Previous studies showed a reduced vasodilatory response to IGF-1 in SHRs, and our results suggest a lack of sensitivity, that is, resistance, to IGF-1R signaling. Endothelial apoptosis and/ or aortic wall hypertrophy may influence pAkt or peNOS levels, but this hypothesis requires further studies using single-cell analysis techniques (e.g., high resolution IHC) to fully resolve the issue. 
Fig. 6 Schematic diagram of the loss of IGF-1 receptor intracellular signaling via the proteolytic cleavage of extracellular receptor domains
Normal Receptor Activity

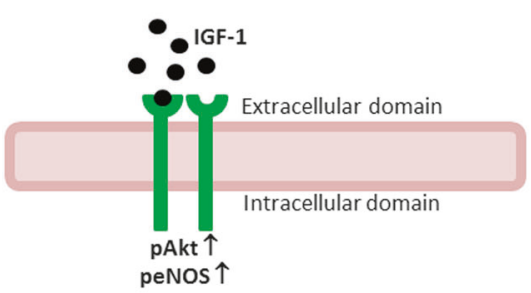

Receptor Cleavage by Extracellular Protease Activity

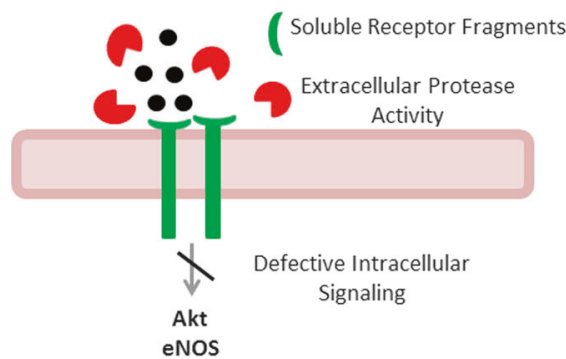

The present study investigated IGF-1R subunits using IHC. We obtained similar immunolabeled areas for IGF-1R beta subunits in fresh aortas of WKY and SHRs. These results are consistent with previous studies that reported similar IGF-1R beta subunit levels in SHRs and Wistar rats using western blotting [13]. IGF-1R alpha-labeled areas in the endothelial layer were significantly lower in the SHR group. The IGF-1R alpha subunit is the ligand-binding region of IGF-1R, and the low pAkt response to IGF- 1 in the SHR group may be associated with reduced ligand binding due to receptor cleavage and the consequent reduction in intracellular signaling (Fig. 6). However, this reduction may not be the only mechanism because reduced tyrosine kinase activity of IGF-1R may also contribute to the reduced IGF-1 response in SHRs, especially because the IGF-1R alphalabeled area along the tunica media was not altered.

A limitation of the current study is that results were obtained in the aorta, which is a conducting artery compared with the arterioles that control peripheral vascular resistance. However, demonstration of a reduced IGF-1 response may be equally important for arterioles and regional blood flow because all endothelial and vascular smooth muscle cells produce IGF-1. A vasodilatory effect of IGF-1 was reported in brachial and coronary arteries and the aorta, and its vasoconstrictor effect was demonstrated in the mesentery artery $[9,10,36]$. Therefore, our findings may be relevant in different vascular segments.

In conclusion, the cellular response to IGF-1 is reduced in the aorta of the SHR hypertension model. MMP receptor cleavage may play a role in the SHR inefficient IGF-1 signaling, and this effect may be important for the elevated peripheral vascular resistance in hypertension besides the proteolytic cleavage of the $\beta_{2}$ adrenergic receptors. IGF-1R cleavage may also be important in other conditions of metabolic diseases and increased protease activity, such as obesity-associated metabolic syndrome, because of the metabolic effects of IGF-1 (e.g., carbohydrate and lipid metabolism).

Acknowledgements This study was supported by National Institute of Health Grant HL 10881 and the Scientific and Technological Research
Council of Turkey (TUBITAK) Postdoctoral Research program, BIDEB-2219. We thank Mr. Frank A. DeLano and Ms. Asimina S. Courelli for their assistance with the experiments.

\section{Compliance with ethical standards}

Conflict of interest The authors declare that they have no conflict of interest.

Open Access This article is licensed under a Creative Commons Attribution-NonCommercial-NoDerivatives 4.0 International License, which permits any non-commercial use, sharing, distribution and reproduction in any medium or format, as long as you give appropriate credit to the original author(s) and the source, and provide a link to the Creative Commons license. You do not have permission under this license to share adapted material derived from this article or parts of it. The images or other third party material in this article are included in the article's Creative Commons license, unless indicated otherwise in a credit line to the material. If material is not included in the article's Creative Commons license and your intended use is not permitted by statutory regulation or exceeds the permitted use, you will need to obtain permission directly from the copyright holder. To view a copy of this license, visit http://creativecommons.org/licenses/by-nc-nd/4.0/.

\section{Appendix material}

The numbers of theoretical cleavage sites in the IGF-1R alpha domain obtained from the protease substrate specificity webserver (PROSPER) https://prosper.erc.monash.edu. $\mathrm{au} /$ webserver.html.

For specific results see: https://prosper.erc.monash.edu. au/result3_queue.pl?id $=$ 4dbc4c69dd164986fc46648b80d0dfb7-88

\section{References}

1. Jones JI, Clemmons DR. Insulin-like growth factors and their binding proteins: biological actions. Endocr Rev. 1995;16:3-34.

2. Stewart CE, Rotwein P. Growth, differentiation, and survival: multiple physiological functions for insulin-like growth factors. Physiol Rev. 1996;76:1005-26.

3. Delafontaine P, Song YH, Li Y. Expression, regulation, and function of IGF-1, IGF-1R, and IGF-1 binding proteins in blood vessels. Arterioscler Thromb Vasc Biol. 2004;24:435-44. 
4. Díez J. Insulin-like growth factor I in essential hypertension. Kidney Int. 1999;55:744-59.

5. Delafontaine P. Insulin-like growth factor I and its binding proteins in the cardiovascular system. Cardiovasc Res. 1995;30:825-34.

6. Tsukahara H, Gordienko DV, Tonshoff B, Gelato MC, Goligorsky MS. Direct demonstration of insulin-like growth factor-I-induced nitric oxide production by endothelial cells. Kidney Int. 1994;45:598-604.

7. Wu HY, Jeng YY, Yue CJ, Chyu K-Y, Hsueh WA, Chan TM. Endothelial dependent vascular effects of insulin and insulin-like growth factor I in the perfused rat mesenteric artery and aortic ring. Diabetes. 1994;43:1027-32.

8. Zeng G, Quon MJ. Insulin-stimulated production of nitric oxide is inhibited by wortmannin. Direct measurement in vascular endothelial cells. J Clin Invest. 1996;98:894-8.

9. Hasdai D, Rizza RA, Holmes DR Jr, Richardson DM, Cohen P, Lerman A. Insulin and insulin-like growth factor-I cause coronary vasorelaxation in vitro. Hypertension. 1998;32:228-34.

10. Pendergrass M, Fazioni E, Collins D, DeFronzo RA. IGF-I increases forearm blood flow without increasing forearm glucose uptake. Am J Physiol. 1998;275(2 Pt 1):E345-50.

11. Lembo G, Rockman HA, Hunter JJ, Steinmetz H, Koch WJ, Ma L, Prinz MP, Ross J Jr, Chien KR, Powell-Braxton L. Elevated blood pressure and enhanced myocardial contractility in mice with severe IGF-1 deficiency. J Clin Invest. 1996;98:2648-55.

12. McCallum RW, Hamilton CA, Graham D, Jardine E, Connell JM, Dominiczak AF. Vascular responses to IGF-I and insulin are impaired in aortae of hypertensive rats. $\mathrm{J}$ Hypertens. 2005;23:351-8.

13. Vecchione C, Colella S, Fratta L, Gentile MT, Selvetella G, Frati G, Trimarco B, Lembo G. Impaired insulin-like growth factor I vasorelaxant effects in hypertension. Hypertension. 2001;37:1480-5.

14. Nishi Y, Katoh T, Okuda T, Yamaguchi T, Kurokawa K. Modulation of renal haemodynamics by IGF-1 is absent in spontaneously hypertensive rats. Kidney Int. 1997;52:165-70.

15. Cohuet G, Struijker-Boudier H. Mechanisms of target organ damage caused by hypertension: therapeutic potential. Pharmacol Ther. 2006;111:81-98.

16. De Meyer GR, Herman AG. Vascular endothelial dysfunction. Prog Cardiovasc Dis. 1997;39:325-42.

17. DeLano FA, Schmid-Schönbein GW. Proteinase activity and receptor cleavage: mechanism for insulin resistance in the spontaneously hypertensive rat. Hypertension. 2008;52:415-23.

18. DeLano FA, Zhang H, Tran EE, Zhang C, Schmid-Schönbein GW. A new hypothesis for insulin resistance in hypertension due to receptor cleavage. Expert Rev Endocrinol Metab. 2010;5:149-58.

19. Delano FA, Chen AY, Wu KI, Tran ED, Rodrigues SF, SchmidSchönbein GW. The autodigestion hypothesis and receptor cleavage in diabetes and hypertension. Drug Discov Today Dis Models. 2011;8:37-46.

20. Tran ED, DeLano FA, Schmid-Schönbein GW. Enhanced matrix metalloproteinase activity in the spontaneously hypertensive rat: VEGFR-2 cleavage, endothelial apoptosis, and capillary rarefaction. J Vasc Res. 2010;47:423-31.
21. Tran ED, Yang M, Chen A, Delano FA, Murfee WL, SchmidSchönbein GW. Matrix metalloproteinase activity causes VEGFR2 cleavage and microvascular rarefaction in rat mesentery. Microcirculation. 2011;18:228-37.

22. Raffetto JD, Khalil RA. Matrix metalloproteinases and their inhibitors in vascular remodeling and vascular disease. Biochem Pharmacol. 2008;75:346-59.

23. Derosa G, Avanzini MA, Geroldi D, Fogari R, Lorini R, De Silvestri A, Tinelli C, Rondini G, d'Annunzio G. Matrix metalloproteinase 2 may be a marker of microangiopathy in children and adolescents with type 1 diabetes mellitus. Diabetes Res Clin Pract. 2005;70:119-25.

24. Glowinska-Olszewska B, Urban M. Elevated matrix metalloproteinase 9 and tissue inhibitor of metalloproteinase 1 in obese children and adolescents. Metab Clin Exp. 2007;56:799-805.

25. Rodrigues SF, Tran ED, Fortes ZB, Schmid-Schönbein GW. Matrix metalloproteinases cleave the beta2-adrenergic receptor in spontaneously hypertensive rats. Am J Physiol Heart Circ Physiol. 2010;299:H25-35.

26. Chen AY, Ha JN, DeLano FA, Schmid-Schönbein GW. Receptor cleavage and P-selectin-dependent reduction of leukocyte adhesion in the spontaneously hypertensive rat. J Leukoc Biol. 2012;92:183-94.

27. Tong S, Neboori HJ, Tran ED, Schmid-Schönbein GW. Constitutive expression and enzymatic cleavage of ICAM-1 in the spontaneously hypertensive rat. J Vasc Res. 2011;48:386-96.

28. Chen AY, DeLano FA, Valdez SR, Shin HY, Schmid-Schönbein GW. Receptor cleavage reduces the fluid shear response in neutrophils of the spontaneously hypertensive rat. Am J Physiol Cell Physiol. 2010;299:C1441-49.

29. Santamaria MH, Chen AY, Chow J, Muñoz DC, SchmidSchönbein GW. Cleavage and reduced CD36 ectodomain density on heart and spleen macrophages in the spontaneously hypertensive rat. Microvasc Res. 2014;95:131-42.

30. Pot C, Chen AY, Ha JN, Schmid-Schönbein GW. Proteolytic cleavage of the red blood cell glycocalyx in a genetic form of hypertension. J Cell Mol Bioeng. 2011;4:678-92.

31. Schmid-Schönbein GW. Inflammation and the autodigestion hypothesis. Microcirculation. 2009;16:289-306.

32. Ren J, Anversa P. The insulin-like growth factor I system: physiological and pathophysiological implication in cardiovascular diseases associated with metabolic syndrome. Biochem Pharmacol. 2015;93:409-17.

33. Spielman LJ, Little JP, Klegeris A. Inflammation and insulin/IGF1 resistance as the possible link between obesity and neurodegeneration. J Neuroimmunol. 2014;273:8-21.

34. Cubbon RM, Kearney MT, Wheatcroft SB. Endothelial IGF-1 receptor signalling in diabetes and insulin resistance. Trends Endocrinol Metab. 2016;27:96-104.

35. Troncoso R, Ibarra C, Vicencio JM, Jaimovich E, Lavandero $\mathrm{S}$. New insights into IGF-1 signaling in the heart. Trends Endocrinol Metab. 2014;25:128-37.

36. Wu H-Y, Jeng YY, Yue C-J, Chyu K-Y, Hsueh WA, Chan TM. Endothelial dependent vascular effects of insulin and insulin-like growth factor I in the perfused rat mesenteric artery and aortic ring. Diabetes. 1994;43:1027-32. 